\title{
Effect of Shear Walls on the Active Vibration Control of Buildings
}

\author{
Mohamed Hechmi El Ouni ${ }^{1,2}$, Mohamed Y. Laissy ${ }^{3}$, Mohammed Ismaeil ${ }^{3, *}$ and \\ Nabil Ben Kahla ${ }^{1,2}$ \\ 1 Department of Civil Engineering, College of Engineering, King Khalid University, Abha 61421, Saudi Arabia; \\ melouni@kku.edu.sa (M.H.E.O.); nbohlal@kku.edu.sa (N.B.K.) \\ 2 Laboratory of Systems and Applied Mechanics, Tunisia Polytechnic School, University of Carthage La \\ Marsa, Tunis 2078, Tunisia \\ 3 Department of Civil Engineering, College of Engineering, University of Prince Mugrin, Almadinah 41499, \\ Saudi Arabia; m.laissy@upm.edu.sa \\ * Correspondence: m.ismaeil@upm.edu.sa
}

Received: 15 October 2018; Accepted: 15 November 2018; Published: 20 November 2018

\begin{abstract}
The study aims to assess the impact of shear walls on active vibration control of the buildings. It has evaluated the design of a smart 20-story building equipped with an Active Mass Damper to mitigate earthquakes. The design has combined shear walls with an Active Mass Damper (AMD) added on the top floor. The control configuration used a force actuator combined with a displacement sensor and was examined with Direct Velocity Feedback. The effect of the presence of wall braces in the design of tall buildings on the performances as well as the control effort has been studied. The results have stated that the shear walls designed for mitigating earthquake loads are capable of reducing the displacement of the tall building somewhat but failed to reduce the acceleration of the top floor. The combination between shear walls and AMD has incredible damping capability on the displacement and acceleration of the building. However, the shear walls tend to increase the control cost since they require more control energy.
\end{abstract}

Keywords: active mass damper; control cost; shear walls; tall buildings; vibration control

\section{Introduction}

Buildings are getting higher, slender, and flexible due to high performance steel, concrete, composite materials, and new techniques of construction. Burj Dubai is the tallest tower in the world with a height of $828 \mathrm{~m}$. These buildings become more sensitive to vibrations induced by natural hazards, which affect the serviceability and occupant comfort and cause structural damage and even failure. Table 1 has listed the deadliest earthquakes on record, according to date, location, number of deaths, and magnitude. The 8.0 magnitude earthquake of Shansi (China) killed 830,000 people on 23 January, 1556. Consequently, vibration control has become a major issue in civil engineering. The main goal of vibration control is to prevent resonance, large amplitude oscillations, and unstable vibration. Research on vibration control provides a solid and necessary foundation to move the frontiers of smart structure technology forward and make this technology a practical alternative. Vibration control strategies are classified into four methods including passive, active, semi-active, and hybrid [1]. These control strategies may be applied to different control designs using a base isolation system that is defined as the bracing system, an auxiliary mass damper, or an auxiliary structure (Connected Buildings Control). The papers reported by Fisco and Adeli [2,3], Korkmaz [4], and Ghaedi et al. [5] provide a detailed review of earlier and recent studies on structural control civil structures. 
The internal damping in flexible structures is often very low and ranges from $0.1 \%$ to $5 \%$. Even a small increase in modal damping might lead to an acceptable reduction in the response using external dampers, devices, or damping materials. The introduction of the passive dampers is fully adequate when the response is mainly governed by resonance. Passive control of buildings has been investigated in depth in the last three decades [6]. Constantinou et al. [1] discussed many passive energy dissipation systems for structural design and retrofit. Castaldo and De Iulisiis [7] proposed an optimal integrated seismic design of structural and viscoelastic bracing-damper systems to control the vibrations of slender buildings by considering the dynamic behavior both of the structural and control systems. Passive dampers are by definition dissipative and stable, which make them reliable and robust. However, they are unable to adapt with changes in environmental, structural, and loading conditions. Furthermore, passive dampers perform inadequatly in connection with very large earthquakes. This has resulted in the evolution of a new type of vibration control called active and semi-active control [8]. They use a set of actuators and sensors connected by feedback or feedforward loops. Active and semi-active control strategies have high performances on the target mode and act indirectly on other modes. Semi-active control devices have become a subject of intensive research because they offer the adaptability of active control devices with minimum energy [9]. Although the active control is expensive in term of energy cost, it is the best control performances and behaves adequately with strong earthquakes [10].

Table 1. The deadliest earthquakes on record.

\begin{tabular}{cclc}
\hline Magnitude & Deaths & \multicolumn{1}{c}{ Location } & Date \\
\hline 8 & 830.000 & Shansi, China & 23 January 1556 \\
7.5 & 255.000 & Tangshan, China & 27 July 1976 \\
9.0 & 225.000 & Off west coast of Northern Sumatra & 26 December 2004 \\
7.0 & 222.570 & Haiti & 12 January 2010 \\
7.9 & 200.000 & Near Xining, Tsinghai, China & 22 May 1927 \\
7.8 & 200.000 & Gansu, China & 16 December 1920 \\
7.9 & 143.000 & Kwanto, Japan & 1 September 1923 \\
7.3 & 110.000 & Ashgabat, Turkmenistan, USSR & 5 October 1948 \\
7.2 & 100.000 & Messina, Italy & 28 December 1908 \\
7.9 & 87.587 & Eastern Sichuan, China & 12 May 2008 \\
7.6 & 80.361 & Pakistan & 8 October 2005 \\
7.6 & 70.000 & Gansu, China & 25 December 1932 \\
8.7 & 70.000 & Lisbon, Portugal & 1 November 1755 \\
7.9 & 66.000 & Peru & 31 May 1970 \\
7.5 & 60.000 & Quetta, Pakistan & 30 May 1935 \\
7.7 & 50.000 & Iran & 20 June 1990 \\
\hline
\end{tabular}

Active control of civil structures was first introduced by Yao [11] as a mean of protecting tall buildings against storms and became the subject of intensive research subsequently. Active Mass Damper (AMD) was proposed by Chang and Soong [12] as an extension of a passive Tuned Mass Damper (TMD) to control the vibrations of tall buildings. Abdel-Rohman [13] presented a process for designing an effective active TMD to control a tall building subjected to stationary random wind forces. Samali et al. [14] investigated the active vibration control of a 40-story building under strong wind excitations using an AMD and compared the results to the case of a classical TMD. Wu and Yang [15] proposed an AMD system to control the Nanjing TV transmission Tower in China by using the Linear Quadratic Gaussian (LQG), Ho, and continuous Sliding Mode Control (SMC) strategies.

Yamamoto et al. [16] presented the response mitigation capabilities of AMD systems installed in four actual steel-frame high-rise buildings in Japan. Ikeda et al. [17] studied the performance of two AMD systems to control both transverse and torsional vibrations of a building based on the LQR control algorithm. Wang and Lin [18] proposed two controllers including the variable structure control and the fuzzy sliding mode control for seismic protection buildings equipped with AMD 
control systems. Guclu and Yazici [19] compared the effectiveness of Fuzzy Logic and PD controllers to control a 15-story frame equipped with AMDs on the first and 15th floors. Zhang et al. [20] studied the Fuzzy Control of seismic structure with an Active Mass Damper experimentally. Tu et al. [21] tested the AMD control system based on a Model Reference Adaptive Control algorithm numerically and experimentally.

Preumont [10] studied the vibration control of a seven story building equipped with an AMD using an unconditionally stable control law. Examining a huge amount of literature on active vibration control showed that the effect of using shear walls in Reinforced Concrete buildings on the active control performances and cost was not investigated yet. There is a dire need to present seismic properties of a building model with improved resistance against earthquakes. Therefore, this study aims to analyze the effect of shear walls on the control performances and control cost. The structural models built in this study would help analyze the seismic performance and energy dissipation capacity in tall buildings. It would also help the less experienced civil engineers in deciding to add shear walls or not while designing a building equipped with an AMD.

\section{Modeling of the Controlled Building}

The section has detailed the modelling of a multi-story building equipped with an AMD. The best mounting location of the AMD is on the top of the structure for controlling the first mode vibration, which causes the largest motions and indirectly the higher modes since the smaller values of mass and spring constant are obtained at the first vibration mode. Figure 1 has shown the building equipped with an AMD attached to the top floor and tuned to the first mode of vibration $\left\{\varnothing_{1}\right\}$, according to the equal peak design procedure.

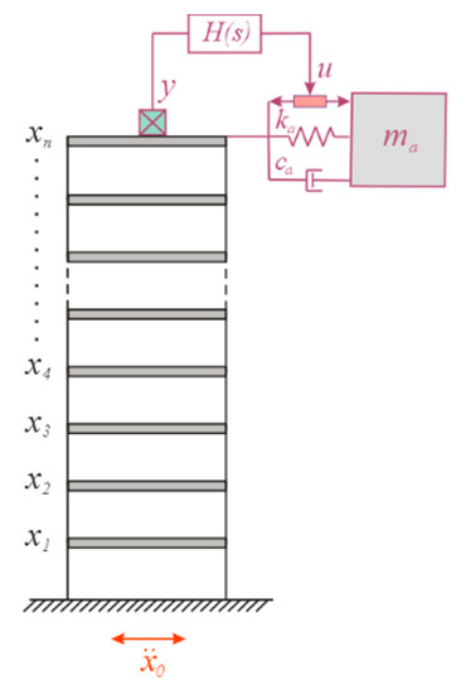

Figure 1. The $n$ story building equipped with an AMD.

The equation of motion will be as follows:

$$
\left[M_{p}\right]\{\ddot{y}\}+\left[C_{p}\right]\{\dot{y}\}+\left[K_{p}\right]\{y\}=-\left[M_{p}\right]\{1\} \ddot{x}_{0}+\{b\} F
$$

where the building characteristic matrices $\left[M_{p}\right],\left[C_{p}\right]$, and $\left[K_{p}\right]$ are of dimension $n+1$ and the displacement vector $\{y\}$ has $n+1$ entry. Therefore, the mass matrix becomes:

$$
\left[M_{p}\right]=\left[\begin{array}{cc}
{[M]_{m x n}} & \{0\}_{n x 1} \\
\{0\}_{n x 1} & m_{a}
\end{array}\right]
$$


The damping matrix is:

$$
\left[C_{p}\right]=\left[\begin{array}{ccc}
{[C]_{(n-1) \times(n-1)}} & \{0\}_{(n-1) \times 1} & \{0\}_{(n-1) \times 1} \\
\{0\}_{1 \times n \times 1} & C_{n n}+C_{a} & -c_{a} \\
\{0\}_{1 \times n x 1} & -c_{a} & c_{a}
\end{array}\right]
$$

The stiffness matrix is:

$$
\left[K_{p}\right]=\left[\begin{array}{ccc}
{[K]_{(n-1) \times(n-1)}} & \{0\}_{(n-1) \times 1} & \{0\}_{(n-1) \times 1} \\
\{0\}_{1 \times n \times 1} & K_{n n}+k_{a} & -k_{a} \\
\{0\}_{1 \times n x 1} & -k_{a} & k_{a}
\end{array}\right]
$$

And the displacement vector is:

$$
\{y\}=\left[\begin{array}{c}
y_{1} \\
\cdot \\
\cdot \\
\cdot \\
y_{n} \\
y_{a}
\end{array}\right]
$$

The vector defining the locations of the control forces is:

$$
\{b\}_{(n+1) \times 1}=\{0 \ldots 0-11\}^{T}
$$

$F$ is the control force in the actuator, which is added to realize the active control. If $m_{a}$ is the mass of the AMD and $M$ is the total mass of the main system, then the following is true.

$$
\mu=\frac{m_{a}}{M}
$$

Mass ratio $=$ absorber mass $/$ main mass

The mass ratio $\mu$ is fixed by the designer based on practical considerations. Typically, a few percent of M result in increased efficiency of the DVA with $\mu$. In this study, $\mu=2 \%$ of total mass of the building. Equation (1) can be written in the following form.

$$
\{\ddot{y}\}=\left(-\left[M_{p}\right]^{-1}\left[K_{p}\right]\right)\{y\}+\left(-\left[M_{p}\right]^{-1}\left[C_{p}\right]\right)\{y\}-[I]\{1\} \ddot{x}_{0}+\left[M_{p}\right]^{-1}\{b\} F
$$

It can also be written as:

$$
\{\ddot{y}\}=\left(-\left[M_{p}\right]^{-1}\left[K_{p}\right]\right)\{y\}+\left(-\left[M_{p}\right]^{-1}\left[C_{p}\right]\right)\{\dot{y}\}\left[M_{p}\right]^{-1}+[-\{1\}\{b\}]\left\{\ddot{x}_{0} F\right\}^{T}
$$

In term of absolute acceleration, the following is true.

$$
\{\ddot{x}\}=\left(-\left[M_{p}\right]^{-1}\left[K_{p}\right]\right)\{y\}+\left(-\left[M_{p}\right]^{-1}\left[C_{p}\right]\right)\{\dot{y}\}-[0]\{1\} \ddot{x}_{0}+\left[M_{p}\right]^{-1}\{b\} F
$$

This equation can be written as:

$$
\left.\{\ddot{x}\}=\left(-\left[M_{p}\right]^{-1}\left[K_{p}\right]\right)\{y\}+\left(-\left[M_{p}\right]^{-1}\left[C_{p}\right]\right)\{\dot{y}\}\left[M_{p}\right]^{-1}+[\dot{[} 0\}\{b\}\right]\left\{\ddot{x}_{0} F\right\}^{T}
$$

Let,

$$
\{X\}=\{\{y\}\{\dot{y}\}\}^{T},\{Y\}=\{\ddot{x}\}, \text { and }\{U\}_{2 \times 1}=\left\{\ddot{x}_{0} F\right\}^{T}
$$


In the state and space form,

$$
\left\{\begin{array}{l}
\{\dot{X}\}=[A]\{X\}+[B]\{U\} \\
\{Y\}=[H]\{X\}+[D]\{U\}
\end{array}\right.
$$

In which,

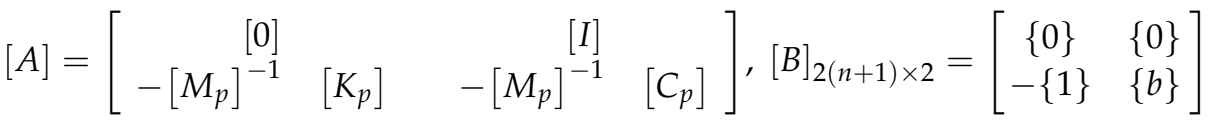

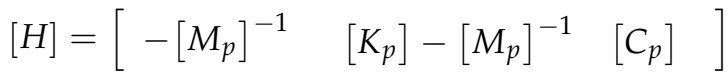

$$
\begin{aligned}
& {[B]_{(n+1) \times 2}=[\{0\}\{b\}]}
\end{aligned}
$$

As far as the sensor is concerned, it is assumed that an absolute velocity sensor is available on the top floor $=\ddot{x}$. This sensor is an accelerometer combined with an integrator. The displacement and acceleration measured at the top floor are also used to evaluate the performances of the control strategy and they are absolute with respect to the ground floor.

As the element of response is analyzed, there are lateral accelerations to the root-locus corresponding to a velocity feedback, which is given by the equation below.

$$
u=-\left(\frac{g}{s}\right) y
$$

where,

$s$ is the Laplace variable

$u$ is the control input.

$y=\ddot{x}$ is the sensor output, (the sensor is an accelerometer combined to an integrator $1 / s$ )

$-(g / s)$ is the feedback control law.

The controller gain $g$ and the corresponding damping added to the structure are determined by using the root locus technique [10].

The shear force is shown below.

$$
f_{0}=k\left(x_{1}-x_{0}\right)
$$

The Root Mean Square (RMS) response $z$ to a white-noise ground acceleration of unit amplitude to identify the critical modes in a design on which the effort should be targeted. It describes the contribution of each mode below the frequency $\omega$ to the structural response. It can be assessed by the following expression.

$$
\sigma_{z}=\left[\int_{0}^{\omega}\left|T_{z x_{0}}\right|^{2} d u\right]^{1 / 2}
$$

where $T_{z x_{0}}$ is the transmissibility between the ground acceleration and the structure response $z$ (e.g., $f_{0}$ or $\ddot{x_{n}}$ ).

The RMS control effort $u$, which eventually fixes the size of the actuator and the running costs, can be assessed from Equation [10].

$$
\sigma_{u}=\left[\int_{0}^{\omega}\left|T_{u x_{0}}\right|^{2} d u\right]^{1 / 2}
$$

where $T_{u \ddot{x}_{0}}$ is the transmissibility between the ground acceleration and the control input. 


\section{Numerical Example}

The study has considered a 20 story Reinforced Concrete building with a total height of $60 \mathrm{~m}$. Each floor has a height of $3 \mathrm{~m}$. The building covers a surface of $625 \mathrm{~m}^{2}$ per floor, which are all used as offices for companies. The building is assumed to be symmetric in both directions. The architecture plan has been identical for all the floors. The symmetry is almost conserved even in the design by using equidistant square columns in both directions to make the modeling simpler. The distance between successive columns is $5 \mathrm{~m}$. The columns are supposed to be fixed to the beams in both directions and also fixed to the raft foundation. Both cases with and without shear walls have been studied (Figure 2). The mass and the stiffness of all floors have been given in Tables 2 and 3, respectively. The natural damping is supposed to be $2 \%$ for all modes, which is adequate for flexible tall RC buildings. For simplification, the 3D uncontrolled building is modeled as a unidirectional lumped mass system with 20 Degrees of Freedom and One degree of freedom is added by implementing the AMD to the top of the building. The mass ratio $\mu$ is equal to $2 \%$ of the total mass of the building.

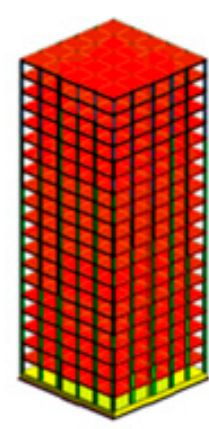

Without shear walls (a)

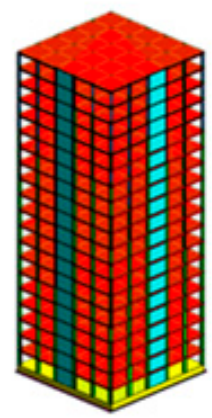

With shear walls

(b)

Figure 2. 3D model of the 20 atory building (a) with shear walls and (b) without shear walls.

Table 2. Mass calculation of each floor for both cases with and without shear walls.

\begin{tabular}{ccc}
\hline Floor & $\begin{array}{c}\text { Floor Mass for Building without } \\
\text { Shear Walls (ton) }\end{array}$ & $\begin{array}{c}\text { Floor Mass for Building with } \\
\text { Shear Walls (ton) }\end{array}$ \\
\hline 1 & 643,795 & 662,020 \\
2 & 643,795 & 662,020 \\
3 & 637,677 & 655,902 \\
4 & 637,677 & 655,902 \\
5 & 632,012 & 650,237 \\
6 & 632,012 & 650,237 \\
7 & 626,800 & 645,025 \\
8 & 626,800 & 645,025 \\
9 & 622,041 & 640,266 \\
10 & 622,041 & 640,266 \\
11 & 617,736 & 635,961 \\
12 & 617,736 & 635,961 \\
13 & 613,883 & 632,108 \\
14 & 613,883 & 632,108 \\
15 & 610,484 & 628,709 \\
16 & 610,484 & 628,709 \\
17 & 607,538 & 625,763 \\
18 & 607,538 & 625,763 \\
19 & 605,046 & 623,271 \\
20 & 605,046 & 623,271 \\
\hline
\end{tabular}


Table 3. Stiffness calculation of each floor for both cases with and without shear walls.

\begin{tabular}{ccc}
\hline Floor & $\begin{array}{c}\text { Floor Stiffness for Building } \\
\text { without Shear Walls (KN/m) }\end{array}$ & $\begin{array}{c}\text { Floor Stiffness for Building with } \\
\text { Shear Walls (KN/m) }\end{array}$ \\
\hline 1 & $8,036,886$ & $14,230,276.8$ \\
2 & $8,036,886$ & $14,230,276.8$ \\
3 & $6,929,764$ & $13,123,154.8$ \\
4 & $6,929,764$ & $13,123,154.8$ \\
5 & $5,904,651$ & $12,098,041.8$ \\
6 & $5,904,651$ & $12,098,041.8$ \\
7 & $4,961,547$ & $11,154,937.9$ \\
8 & $4,961,547$ & $11,154,937.9$ \\
9 & $4,100,452$ & $10,293,842.9$ \\
10 & $4,100,452$ & $10,293,842.9$ \\
11 & $3,321,366$ & $9,514,757.07$ \\
12 & $3,321,366$ & $9,514,757.07$ \\
13 & $2,624,289$ & $8,817,680.24$ \\
14 & $2,624,289$ & $8,817,680.24$ \\
15 & $2,009,221$ & $8,202,612.44$ \\
16 & $2,009,221$ & $8,202,612.44$ \\
17 & $1,476,163$ & $7,669,553.69$ \\
18 & $1,476,163$ & $7,669,553.69$ \\
19 & $1,025,113$ & $7,218,503.97$ \\
20 & $1,025,113$ & $7,218,503.97$ \\
\hline
\end{tabular}

\section{Results and Discussion}

The active control of the cases of buildings with and without shear walls have been compared. The control of both structures has been studied with a special focus on the control effort, which provides the control cost.

\subsection{Effect of Shear Walls on the Building Response before Adding the Active Control}

Adding shear walls may be classified as a passive structural control, which may be a cheap and efficient solution in case of moderate earthquakes and small buildings. The effect of adding shear walls on the response of the tall building under ELCENTRO earthquake excitation has been studied without adding active damping (Figure 3). The time response of the top floor displacement of the building subjected to the EL Centro earthquake for cases with and without shear walls (uncontrolled). The displacement amplitude was reduced by adding shear walls but displacement amplitudes still reach $11 \mathrm{~cm}$, which may affect the resistance or the comfort of the building. The shear walls are not efficient in reducing the acceleration amplitude by observing the time response of the top floor acceleration of a 20-story building subjected to the El Centro earthquake for cases with and without shear walls (Figure 4).

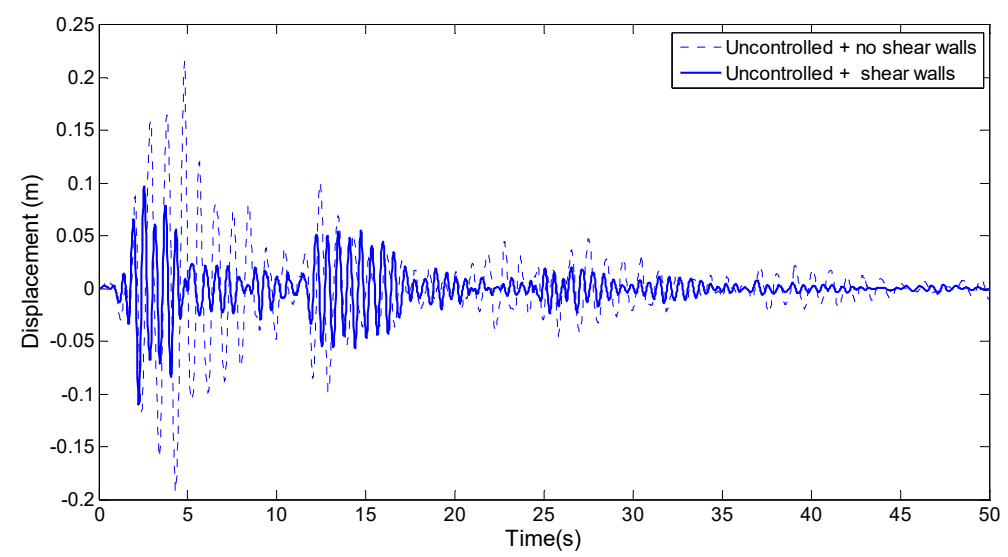

Figure 3. Time response of the top floor displacement of a 20-story building subjected to the EL Centro earthquake for cases with and without shear walls (uncontrolled). 


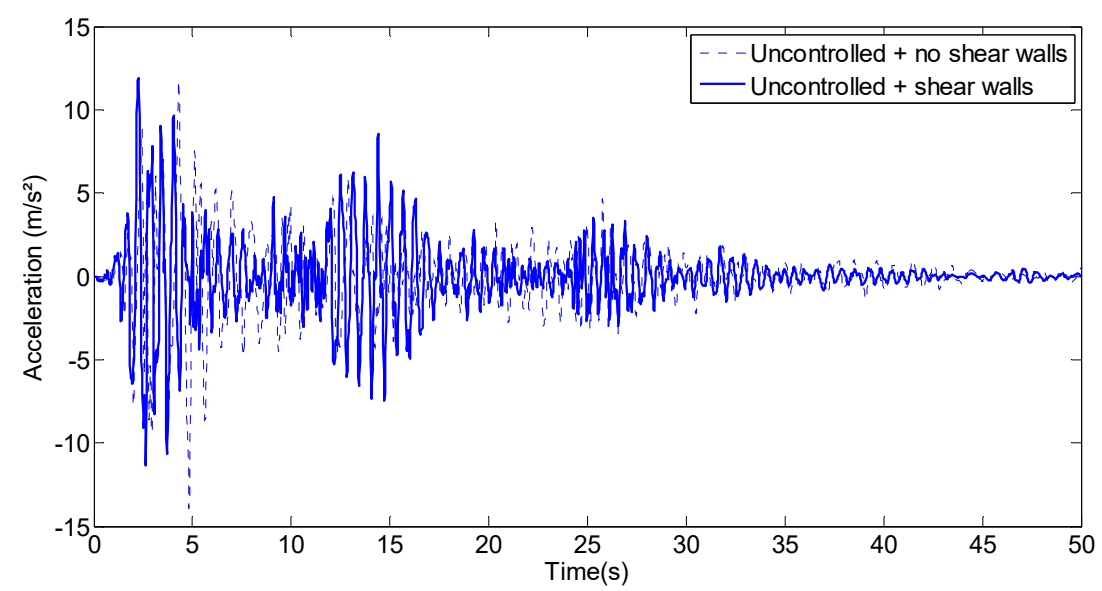

Figure 4. Time response of the top floor acceleration of a 20-story building subjected to the EL Centro earthquake for cases with and without shear walls (uncontrolled).

\subsection{Comparison between Active Control Cases with and without Shear Walls}

The controller gain and the corresponding damping added to the structure are determined using the root locus technique [10]. The time responses of the controlled and uncontrolled top floor displacements of the building subjected to the EL Centro earthquake for cases with and without shear walls have been plotted in Figure 5. When AMD and shear walls are used separately, they may reduce the amplitudes of top floor displacement. AMD seems more efficient than the shear added walls. The top floor displacements are attractively damped by using both AMD and shear walls simultaneously.

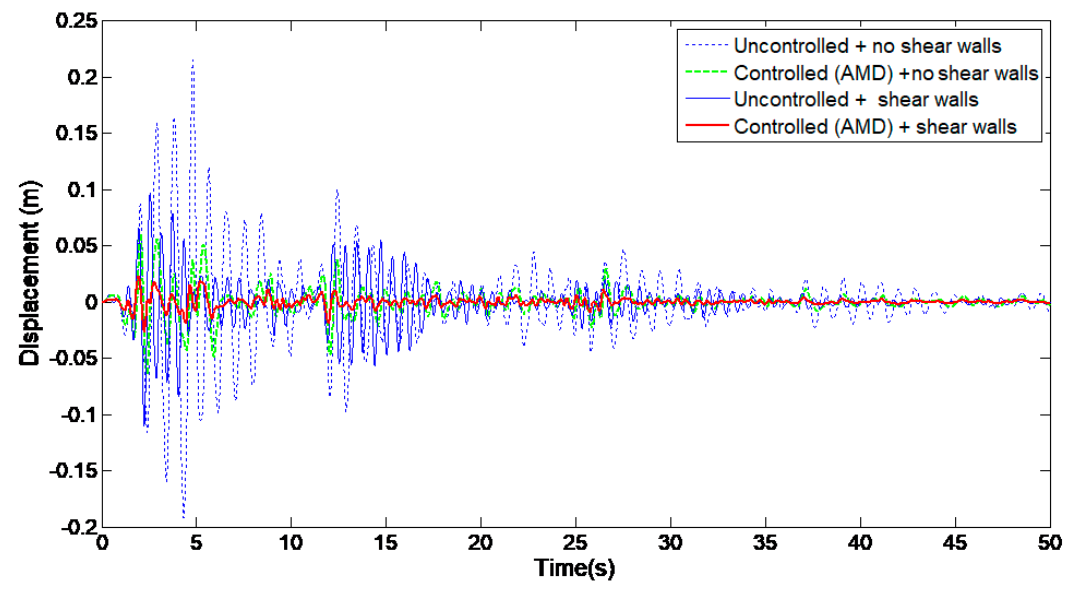

Figure 5. Time response of the controlled and uncontrolled top floor displacements of the building subjected to the EL Centro earthquake for cases with and without shear walls.

The time responses of the controlled and uncontrolled top floor accelerations of the building subjected to the EL Centro earthquake for cases with and without shear walls are plotted in Figure 6. When shear walls are used without control, it cannot reduce the amplitudes of top floor acceleration. However, AMD successfully reduced the acceleration amplitude. The most efficient and the top floor acceleration is attractively damped by using both AMD and shear walls simultaneously. In the frequency domain, Figure 7 has plotted the transmissibility between the ground acceleration and the top floor acceleration with respect to the maximum damping on the first mode. The case of control using only AMD is efficient in controlling all modes but attractive results are obtained when shear walls are combined with AMD. Therefore, the strategy combining shear walls with AMD is the most efficient. 


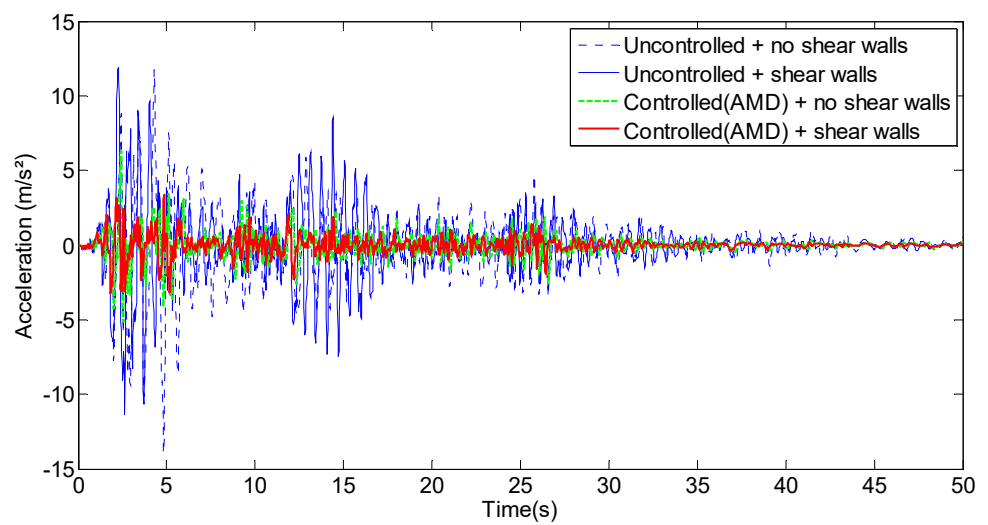

Figure 6. Time response of the controlled and uncontrolled top floor accelerations of the building subjected to EL Centro earthquake for cases with and without shear walls.

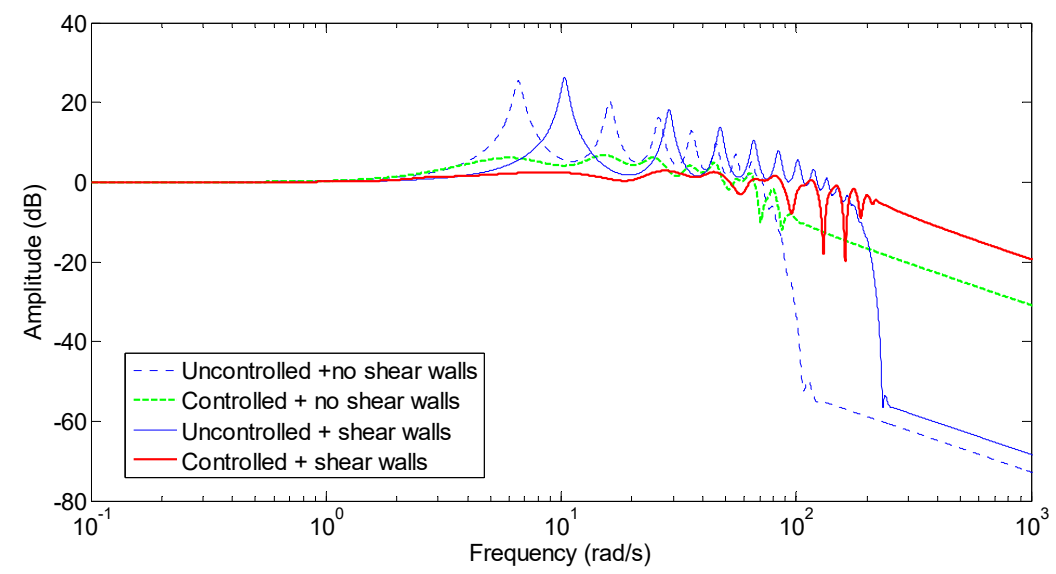

Figure 7. The transmissibility between the ground acceleration and the top floor acceleration with respect to the maximum damping on the first mode.

Depending on the designer objectives, the performances may not be the only criterion to design a control strategy. The control effort must be calculated in order to estimate the control cost since it is an important factor. The cases of active control with and without shear walls are compared in term of the control effort. Figure 8 has plotted the RMS control efforts for both cases. The case of AMD with shear walls seems more expensive than the case without shear walls.

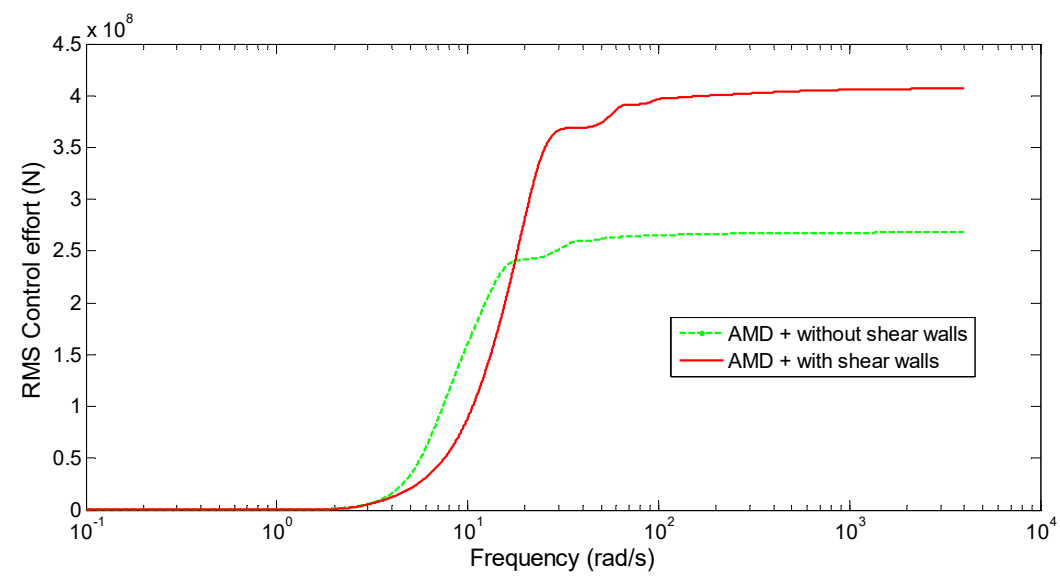

Figure 8. RMS control effort for cases of control with and without shear walls.

Earthquakes are likely to cause damage to the building structures. The shear walls may reduce the seismic effect on the building and may solve the problem for low earthquake excitations. The passive 
tuned mass damper is widely used for medium earthquakes [22-30]. However, the AMD has the best performance in mitigating earthquakes for strong earthquakes. However, some engineers use shear walls during the design of the building equipped with AMDwhile others do not use them. This has brought some confusion to the less experienced civil engineers. The present study has investigated the effect of the shear walls on the performances of the AMD and on the control cost. It has shown that shear walls without AMD are somewhat capable of reducing the displacements in tall building. However, they fail to reduce the acceleration of the top floor. Both displacment and acceleration of the building are attractively damped by adding an AMD to a building with shear walls. It has been shown that the AMD works better with shear walls as compared to without shear walls. The total cost of the control estimated in term of control effort is higher than the case without shear walls. Therefore, the designer should find a compromise between the two solutions to optimize his final choice. This may be possible after carrying out a parametric study by varying the number and dimensions of the shear walls. The perspectives of this work have focused on this feature to optimize the proposed strategy.

\section{Conclusions}

The study has investigated the active vibration control of a tall building equipped with an AMDMass to mitigate the earthquakes. The control configuration used a force actuator combined with a displacement sensor and is examined with the Direct Velocity Feedback control law. The effect of presence on wall braces in the design of tall buildings on the control effort has also been studied. The shear walls are somewhat capable of reducing the displacement of tall buildings but fail to reduce the acceleration of the top floor. The AMD reduces both the displacement and acceleration of the top floor, attractively. Incredible damping capability is obtained by combining shear walls and ADM but total cost of the control estimated in term of the control effort was higher than the case without shear walls. Future work needs to apply semi-active damping for reducing the high cost of the active control. Different types of dampers can be combined with the shear walls to obtain the best performances with a low cost of energy required.

Author Contributions: This paper is a collective work done by all the authors. M.H.E.O. created the model of the building with Active Mass Damper on MATLAB. M.Y.L. Supervised the work and contributed in the interpretation of the results and took care of the revision of the paper. M.I. Calculated the data (stiffness, mass, damping) of the tall building with and without shear walls. N.B.K. is the supervisor of the work and solved the programming errors found in Matlab.

Funding: This research is not funded by any resource.

Acknowledgments: The authors would like to express their gratitude to King Khalid University, Saudi Arabia for providing administrative and technical support.

Conflicts of Interest: The authors declare no conflicts of interest.

\section{References}

1. Constantinou, M.C.; Soong, T.T.; Dargush, G.F. Passive Energy Dissipation Systems for Structural Design and Retrofit; Multidisciplinary Center for Earthquake Engineering Research: Buffalo, NY, USA, 1998.

2. Fisco, N.R.; Adeli, H. Smart structures: Part I-Active and semi-active control. Sci. Iran. 2011, 18, $275-284$. [CrossRef]

3. Fisco, N.R.; Adeli, H. Smart structures: Part II-Hybrid control systems and control strategies. Sci. Iran. 2011, 18, 285-295. [CrossRef]

4. Korkmaz, S. A review of active structural control: Challenges for engineering informatics. Comput. Struct. 2011, 89, 2113-2132. [CrossRef]

5. Ghaedi, K.; Ibrahim, Z.; Adeli, H.; Javanmardi, A. Invited Review: Recent developments in vibration control of building and bridge structures. J. Vibroeng. 2017, 19, 3564-3580. [CrossRef]

6. Soong, T.T.; Dargush, G.F. Passive Energy Dissipation Systems in Structural Engineering; Wiley and Sons Ltd.: Chichester, UK, 1997. 
7. Castaldo, P.; De Iulisiis, M. Optimal integrated seismic design of structural and viscoelastic bracing-damper systems. Earthq. Eng. Struct. Dyn. 2014, 43, 1809-1827. [CrossRef]

8. Soong, T.T.; Constantinou, M.C. Passive and Active Structural Vibration Control in Civil Engineering; Springer: New York, NY, USA, 1994.

9. De Iuliis, M.; Castaldo, P. An energy-based approach to the seismic control of one-way asymmetrical structural systems using semi-active devices. Int. J. Earthq. Eng. 2012, 29, 31-42.

10. Preumont, A.; Seto, K. Active Control of Structures; Wiley \& Sons, Ltd.: Chichester, UK, 2008.

11. Yao, J.T.P. Concept of structure control. ASCE J. Struct. Div. 1972, 98, 1567-1574.

12. Chang, J.C.; Soong, T.T. Structural control using active tuned mass dampers. J. Eng. Mech. Div. 1980, 106, 1091-1098.

13. Abdel-Rohman, M. Optimal design of active TMD for buildings control. Build. Environ. 1984, 19, $191-195$. [CrossRef]

14. Samali, B.; Yang, J.N.; Yeh, C.T. Control of lateral-torsional motion of wind-excited buildings. J. Eng. Mech. 1985, 111, 777-796. [CrossRef]

15. Wu, J.C.; Yang, J.N. Active control of transmission tower under stochastic wind. J. Struct. Eng. 1998, 124, 1302-1312. [CrossRef]

16. Yamada, Y.; Ikawa, N.; Yokoyama, H.; Tachibana, E. Active control of structures using the joining member with negative stiffness. In Proceedings of the First World Conference on Structural Control, Los Angeles, CA, USA, 3-5 August 1994.

17. Ikeda, Y.; Sasaki, K.; Sakamoto, M.; Kobori, T. Active mass driver system as the first application of active structural control. Earthq. Eng. Struct. Dyn. 2001, 30, 1575-1595. [CrossRef]

18. Wang, A.P.; Lin, Y.H. Vibration control of a tall building subjected to earthquake excitation. J. Sound Vib. 2007, 299, 757-773. [CrossRef]

19. Guclu, R.; Yazici, H. Vibration control of a structure with ATMD against earthquake using fuzzy logic controllers. J. Sound Vib. 2008, 318, 36-49. [CrossRef]

20. Zhang, W.; Liu, X.; Xu, G. Fuzzy Control of Seismic Structure with an Active Mass Damper. In Proceedings of the 6th International Conference on Advances in Experimental Structural Engineering, Champaign, IL, USA, 1-2 August 2015.

21. Tu, J.; Lin, X.; Tu, B.; Xu, J.; Tan, D. Simulation and experimental tests on active mass damper control system based on model reference adaptive control algorithm. J. Sound Vib. 2014, 333, 4826-4842. [CrossRef]

22. Roffel, A.J.; Narasimhan, S. Extended Kalman filter for modal identification of structures equipped with a pendulum tuned mass damper. J. Sound Vib. 2014, 333, 6038-6056. [CrossRef]

23. Roffel, A.J.; Narasimhan, S.; Haskett, T. Performance of pendulum tuned mass dampers in reducing the responses of flexible structures. J. Struct. Eng. 2012, 139, 04013019. [CrossRef]

24. Tuan, A.Y.; Shang, G.Q. Vibration control in a 101-storey building using a tuned mass damper. Tamkang Univ. Sci. Technol. 2014, 17, 141-156.

25. Han, B.; Li, C. Characteristics of linearly distributed parameter-based multiple-tuned mass dampers. Struct. Control Health Monit. 2008, 15, 839-856. [CrossRef]

26. $\mathrm{Li}, \mathrm{C}$. Performance of multiple tuned mass dampers for attenuating undesirable oscillations of structures under the ground acceleration. Earthq. Eng. Struct. Dyn. 2000, 29, 1405-1421. [CrossRef]

27. Li, C. Optimum multiple tuned mass dampers for structures under the ground acceleration based on DDMF and ADMF. Earthq. Eng. Struct. Dyn. 2002, 31, 897-919. [CrossRef]

28. Aly, A.M. Proposed robust tuned mass damper for response mitigation in buildings exposed to multidirectional wind. Struct. Des. Tall Spec. Build. 2014, 23, 664-691. [CrossRef]

29. Elias, S. Seismic Energy Assessment of Buildings with Tuned Vibration Absorbers. Shock Vib. 2018, 2018, 2051687. [CrossRef]

30. Wu, Q.; Zhao, W.; Zhu, W.; Zheng, R.; Zhao, X. A Tuned Mass Damper with Nonlinear Magnetic Force for Vibration Suppression with Wide Frequency Range of Offshore Platform under Earthquake Loads. Shock Vib. 2018, 2018, 1505061. [CrossRef]

(C) 2018 by the authors. Licensee MDPI, Basel, Switzerland. This article is an open access article distributed under the terms and conditions of the Creative Commons Attribution (CC BY) license (http://creativecommons.org/licenses/by/4.0/). 